\title{
Focus on the person, not the problem
}

\author{
Sophie Cook UK research editor
}

The BMJ

The NHS is strapped for cash, and doctors must be part of any solution. But how should we respond to demands for ever greater productivity and efficiency? We are encouraged to practise evidence based medicine in a cost effective way. But it's not always clear when to intervene and when to watch and wait. Evidence to guide decisions often conflicts or is absent; the needs and preferences of our patients differ. There are more grey areas than black and white.

This week Jason Powell and colleagues tackle the uncertainty in managing recurrent tonsillitis in adults (doi:10.1136/bmj. $\mathrm{j} 1450$ ). Tonsillectomy is a "relatively ineffective intervention," say clinical commissioning groups, and GPs feel under pressure to reduce referrals. But some patients perceive "a barrier to the treatment they desire." The authors' solution is to listen to how symptoms affect a person's quality of life, encourage open discussion about the risks and benefits of all options, and support a shared decision. This seems sound and transferable advice.

Miranda Wolpert and colleagues take the same approach: focusing on the person, not the problem, to overcome failings in children's mental health services (doi:10.1136/bmj.j1500).

"Clinical evidence is not enough," they say. "The preferences of those accessing services should be a core part of decision making and health management and support."

Children and their parents look likely to benefit from the "Quick-Wee" method studied by Kaufman and colleagues (doi:10.1136/bmj.j1341). They found that simple suprapubic stimulation with gauze soaked in cold fluid increased voiding within five minutes in infants who required a urine sample, when compared with the standard clean catch method. In an accompanying editorial (doi:10.1136/bmj.j1684) Anna Kilonback explains that this is the first trial to show effectiveness of an intervention that is likely to be acceptable to parents and practitioners. It's a method that "could and probably should be incorporated into guidelines," she says.

Finally, Margaret McCartney doubts the cost effectiveness of Scotland's pledge to provide baby boxes to all newborns (doi:10. 1136/bmj.j1766). Though the policy, inspired by the Finnish baby box, might please the recipients, McCartney says that there is little evidence to support this costly intervention and suggests other "less cute" spending options. With cash in short supply, evidence and patients' preferences must inform our practice. 